Original article

\title{
Schizophrenia in type 2 diabetes mellitus: Prevalence and clinical characteristics
}

\author{
Chun-Jen Huang ${ }^{\mathrm{a}, \mathrm{b}}$, Hui-Min Hsieh ${ }^{\mathrm{c}}$, Hung-Pin $\mathrm{Tu}^{\mathrm{d}}$, He-Jiun Jiang ${ }^{\mathrm{e}}$, Peng-Wei Wang ${ }^{\mathrm{a}, \mathrm{b}}$, \\ Ching-Hua Lin $^{\mathrm{b}, \mathrm{f}, *}$ \\ a Department of Psychiatry, Kaohsiung Medical University Hospital, Taiwan \\ ${ }^{\mathrm{b}}$ Department of Psychiatry, Faculty of Medicine, College of Medicine, Kaohsiung Medical University, Kaohsiung, Taiwan \\ ${ }^{\mathrm{c}}$ Department of Public Health, Kaohsiung Medical University, Taiwan \\ d Department of Public Health and Environmental Medicine, School of Medicine, College of Medicine, Kaohsiung Medical University, Taiwan \\ e Division of Endocrinology and Metabolism, Department of Internal Medicine, Kaohsiung Medical University Hospital, Kaohsiung Medical University, \\ Kaohsiung, Taiwan \\ ${ }^{\mathrm{f}}$ Department of Adult Psychiatry, Kai-Suan Psychiatric Hospital, Kaohsiung, Taiwan
}

\section{A R T I C L E I N F O}

\section{Article history:}

Received 13 May 2018

Received in revised form 14 August 2018

Accepted 18 August 2018

Available online 4 September 2018

\section{Keywords:}

National Health Insurance

Prevalence

Schizophrenia

Type 2 diabetes mellitus

\begin{abstract}
A B S T R A C T
Background: This study investigated the prevalence and characteristics of schizophrenia in patients with type 2 diabetes mellitus (T2DM) in Taiwan.

Methods: National Health Insurance claims data for patients with principal diagnoses of schizophrenia and T2DM were analysed.

Results: Compared with patients with schizophrenia in the general population (GP), those with schizophrenia and T2DM were more likely to have higher Charlson comorbidity index (CCI) scores and multiple comorbidities, and were older. The prevalence of schizophrenia was significantly higher in patients with T2DM than in the GP from 2000 to 2010. In addition, during this period, the prevalence of schizophrenia in patients with T2DM increased from $0.64 \%$ to $0.85 \%$; such an increase in the GP was also observed. A high prevalence of schizophrenia was observed in patients with T2DM aged less than 60 years old; those residing in eastern Taiwan; those with incomes of $\leq \mathrm{NT} \$ 17,280$, NT\$17,281-NT\$22,880, NT\$22,881-NT\$28,800, and NT\$36,301-NT\$45,800; and those with $\mathrm{CCI}>2$.

Conclusions: Our study found the prevalence of schizophrenia is higher in patients with T2DM than in the GP, particularly those with earlier ages less than 60 years old. Public health initiatives are necessary to prevent and treat schizophrenia in patients with T2DM, specifically for those with the aforementioned and premature death risk.
\end{abstract}

(C) 2018 Elsevier Masson SAS. All rights reserved.

\section{Introduction}

Schizophrenia is a psychotic disorder that is often chronic and negatively affects a patient's quality of life [1]. Schizophrenia has a lifetime prevalence of $1.0 \%-1.5 \%$ [2,3]. Schizophrenia is associated with substantial premature death and mortality rate twice as high as that of the general population (GP) [4-6]. One meta-analysis by Carsten Hjorthøj and colleagues showed that patients with schizophrenia die 14.5 years earlier than general population and noted an urgent need for interventions to bridge the mortality gap for patients with schizophrenia, in particular to deal with metabolic syndrome and risks of vascular complications.
Diabetes mellitus (DM) is an endocrine and metabolic disorders with impaired insulin secretion and insulin resistance leading to hyperglycemia and may cause macrovascular and microvascular complications [7]. DM and its complications impose a heavy burden not only at the personal level but also the global level $[8,9]$. In Asia, type $2 \mathrm{DM}$ (T2DM) became a major public health concern for ethnic Chinese populations in mainland China, Hong Kong, Taiwan, and Singapore, and the prevalence of T2DM among the adult ethnic Chinese populations in these countries has reached $20 \%[8,10]$.

Schizophrenia has high endogenous risk with diabetes [11]. In 1879, Sir Henry Maudsley in Pathology of Mind wrote, 'Diabetes is a

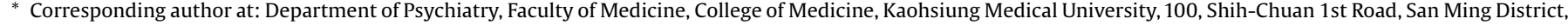
Kaohsiung 807, Taiwan.

E-mail address: chua.lin@msa.hinet.net (C.-H. Lin).
} 
disease which often shows itself in families in which insanity prevails' [12]. In addition, leading researchers such as Kraepelin E. (1983) and Bleuler, E. (1911) had discussed whether altered energy metabolism should be part of the disease picture of schizophrenia [13]. Long before antipsychotic drugs became a standard type of therapy, studies had shown abnormal glucose tolerance in patients with 'dementia praecox' (schizophrenia) [11,14,15]. Rajkumar et al. found individuals with schizophrenia were at an approximately three times higher risk of diabetes than the general population before receiving any antipsychotics mediations (drug-naïve). This finding demonstrated that diabetes is associated with schizophrenia independently of treatment with antipsychotic drugs [11].

Existing evidences for the genetic correlation between schizophrenia and T2DM were still mixed. One current study used data from genome-wide association studies to test the presence of causal relationships between schizophrenia and T2DM and found no causal relationships or shared mechanisms between schizophrenia and impaired glucose homeostasis [16]. On the other hand, many studies suggested schizophrenia and T2DM may share genetic (such as TCF7L2 Gene) and familial risk factors [13,17,18]. Gene pathways that have been associated with T2DM and schizophrenia may include calcium, g-secretase-mediated ErbB4, adipocytokine, insulin, and AKT signaling [19]. The genetic variants may increase both the risk of diabetes and vulnerability to schizophrenia [20].

Many studies have examined incidence or prevalence of diabetes in patients with schizophrenia given the possible onset of schizophrenia is much earlier than the T2DM [21-25]. However, very few have investigated the prevalence of schizophrenia among patients with T2DM. The prevalence of schizophrenia in patients with T2DM will not only reflect the proportion of a T2DM population that has onset risk of schizophrenia at a certain point of time before they developed T2DM, but also will reflect the potential premature mortality risks that may affect the duration of the schizophrenia in patients with T2D. Therefore, this study aimed to investigate the prevalence of schizophrenia in patients with T2DM using the Taiwan National Health Insurance (NHI) database and provide information on public health promotion efforts. Specifically, we first investigated the prevalence of schizophrenia in patients with T2DM from 2000 to 2010 and then compared factors for schizophrenia associated with these patients and the general population. Finally, we analysed the risk factors associated with schizophrenia in patients with T2DM.

\section{Methods}

\subsection{Data source}

The Taiwan NHI program is a mandatory, single-payer system that was established in 1995; approximately 98\% of Taiwanese residents are enrolled in the NHI program, and almost all medical care providers in Taiwan, including those employed at medical and primary care centres, are contracted by the NHI Administration (NHIA) to provide outpatient and inpatient services. All health care providers make claims to the $\mathrm{NHI}$ to receive monthly reimbursements for their medical fees. Related claim records include inpatient, ambulatory, and home care visits and associated information such as patient demographic characteristics, clinical details, health care utilisation, and expenditure.

\subsection{Sample}

This retrospective cohort study analysed a random sample of patients selected from all NHI enrolees from 2000 to 2010. In 2010, the $\mathrm{NHI}$ program provided the medical claims data of 1 million randomly selected patients (approximately $4.5 \%$ of all enrolees) for research on health services. The registration and claims data collected by the NHI program for these patients constitutes the Longitudinal Health Insurance Database 2010 (LHID 2010). The sample group did not significantly differ from all enrolees in terms of age, sex, or average insured payroll-related amount. This study analysed a sample of 715,756 patients aged $\geq 20$ years from the LHID 2010 .

\subsection{Definitions of T2DM and schizophrenia}

The Taiwan NHI claims data are based on the International Classification of Diseases, Ninth Revision, Clinical Modification (ICD-9-CM) diagnostic codes. These data provided a useful structure for using ICD-9-CM diagnostic codes to identify patients with T2DM and schizophrenia. This study analysed patients who had at least two service claims for ambulatory care or one service claim for inpatient care for a principal diagnosis of T2DM (ICD-9CM codes 250.x0 and 250.x2) [26-28]. To deal with patients may have a diagnosis of schizophrenia in one but none of the subsequent contacts, we followed Chien et al. approach and defined schizophrenia as a record of at least one outpatient or inpatient service claim for a principal diagnosis of schizophrenia (ICD-9-CM code 295.xx) from 2000 to 2010 [21,29,30].

\subsection{Prevalence of schizophrenia}

The prevalence of schizophrenia in the GP was calculated by dividing the number of patients with schizophrenia by the total number of study patients. The prevalence of schizophrenia in patients with T2DM was calculated by dividing the total number of patients with T2DM by the number of patients with schizophrenia.

\subsection{Measurements}

The demographic characteristics of the patients, including age, sex, residential area, residential urbanisation level, income, comorbidities, Charlson Comorbidity Index (CCI), and duration of DM, were obtained from each patient file retrieved from the NHI database. Patients were classified into seven age groups, namely 20-30, 31-40, 41-50, 51-60, 61-70, 71-80, and $\geq 80$ years. Residential area was classified into five geographical regions of Taiwan, namely northern, central, southern, and eastern Taiwan and offshore islets or other areas. Urbanisation level was categorised as rural or urban. Average monthly income was classified into six categories: $\leq \mathrm{NT} \$ 17,280$, NT\$17,281-NT\$22,880, NT\$22,881-NT\$28,800, NT\$28,801-NT\$36,300, NT\$36,301-NT $\$ 45,800$, and $>\mathrm{NT} \$ 45,800$. Comorbidities included myocardial infarction, congestive heart failure, peripheral vascular disease, hemiplegia or paraplegia, renal disease, and cerebrovascular disease. The CCIs were defined as $0,1-2$, and $>2$. The duration of DM (years) was classified into four categories: $\leq 3,3-6$ (including the sixth year), 6-9 (including the ninth year), and $>9$.

Oral antidiabetic therapy (ADT) was categorised into five groups: metformin (anatomical therapeutic chemical [ATC] code A10BA), sulfonylureas (ATC code A10BB), meglitinides (ATC code A10BX), thiazolidinediones (ATC code A10BG), and an $\alpha$-glucosidase inhibitor (ATC code A10BF). Insulin injection therapy was classified as rapid-acting (ATC code A10AB), intermediate-acting (ATC code A10AC), long-acting (ATC code A10AE), and combination (ATC code A10AD) therapy.

\subsection{Statistical analysis}

The distribution of characteristics was compared among the three groups of patients, namely T2DM with schizophrenia, T2DM without schizophrenia, and the GP. Chi-squared $\left(\chi^{2}\right)$ and $t$ tests were conducted to determine categorical and continuous variables, respectively. Generalised linear mixed models assuming a 
Poisson distribution were used to compare the prevalence of schizophrenia in patients with T2DM and the GP. The prevalence ratios (PRs) in the T2DM and GP groups were calculated and compared using a log-binomial model. A multiple logistic regression model was used to estimate the adjusted odds ratio with a 95\% confidence interval (CI) for determining the association between schizophrenia and T2DM in patients with T2DM, as well as the independent risk factors. The Joinpoint Regression Program (Version 4.2.0.2; National Cancer Institute, Bethesda, MD, USA) was used to estimate trends related to the prevalence of schizophrenia. Statistical analyses were performed using SAS (version 9.4, SAS Institute Inc., Cary, NC, USA). Statistical tests were double-sided and $p$ value $<0.05$ was considered statistically significant.

\section{Results}

Table 1 shows the demographic characteristics of the patients in all three groups, (T2DM with schizophrenia group $n=532, T 2 D M$ without schizophrenia group $n=61,835$, and the GP group $n=715,756$ ) including age, sex, residential area, urbanisation level, income, comorbidities, CCI score, and duration of DM in 2010. Except for urbanisation level, comorbidities (congestive heart failure, hemiplegia or paraplegia, and renal disease) and $\mathrm{CCI}$, the demographic characteristics significantly differed between the T2DM with schizophrenia and T2DM without schizophrenia groups. Except for sex, urbanisation, and comorbidities (myocardial infarction), all demographic characteristics significantly differed between the GP and T2DM with schizophrenia groups. All demographic characteristics significantly differed between the GP and T2DM without schizophrenia groups.

Fig. 1 compares the temporal trends in the prevalence of schizophrenia from 2000 to 2010. During this period, the prevalence of schizophrenia increased from $0.64 \%$ to $0.85 \%$ in the T2DM group and from $0.37 \%$ to $0.56 \%$ in the GP group. The prevalence was significantly $(\mathrm{P}<0.0001)$ higher in the T2DM group than in the GP group. The annual PRs for schizophrenia in the

Table 1

Characteristics of type 2 diabetes mellitus with and without schizophrenia, and general population in year 2010.

\begin{tabular}{|c|c|c|c|c|c|c|}
\hline & T2DM with schizophrenia & T2DM without schizophrenia & GP & $\mathrm{P}_{1}{ }^{\mathrm{c}}$ & $\mathrm{P}_{2}^{\mathrm{c}}$ & $\mathrm{P}_{3}{ }^{\mathrm{C}}$ \\
\hline $\mathrm{n}$ & 532 & 61,835 & 715,756 & & & \\
\hline Age mean(SD), years & $53.8(12.2)$ & $62.6(13.1)$ & $44.5(16.0)$ & $<0.0001$ & $<0.0001$ & $<0.0001$ \\
\hline \multicolumn{7}{|l|}{ Age group, $n(\%)$} \\
\hline $20-30$ & $5(0.9)$ & $610(1.0)$ & $150,017(21.0)$ & & & \\
\hline $31-40$ & $58(10.9)$ & $2358(3.8)$ & $168,180(23.5)$ & & & \\
\hline $41-50$ & $145(27.3)$ & $7297(11.8)$ & $154,120(21.5)$ & & & \\
\hline $51-60$ & $187(35.2)$ & $16,487(26.7)$ & $125,318(17.5)$ & & & \\
\hline $61-70$ & $73(13.7)$ & $16,201(26.2)$ & $59,114(8.3)$ & & & \\
\hline $71-80$ & $52(9.8)$ & $12,781(20.7)$ & $37,519(5.2)$ & & & \\
\hline$>80$ & $12(2.3)$ & $6101(9.9)$ & $21,488(3.0)$ & $<0.0001$ & $<0.0001$ & $<0.0001$ \\
\hline \multicolumn{7}{|l|}{ Sex, n (\%) } \\
\hline Males & $243(45.7)$ & $31,024(50.2)$ & $345,736(48.3)$ & & & \\
\hline Females & $289(54.3)$ & $30,811(49.8)$ & $370,020(51.7)$ & 0.0389 & 0.2255 & $<0.0001$ \\
\hline \multicolumn{7}{|l|}{ Region, n (\%) } \\
\hline Northern & $237(44.5)$ & $28,240(45.7)$ & 343,067 (47.9) & & & \\
\hline Central & $99(18.6)$ & $14,275(23.1)$ & $167,093(23.3)$ & & & \\
\hline Southern & $161(30.3)$ & $17,037(27.6)$ & $183,341(25.6)$ & & & \\
\hline Eastern & $31(5.8)$ & $1665(2.7)$ & $16,174(2.3)$ & & & \\
\hline Offshore islets and other & $4(0.8)$ & $618(1.0)$ & $6081(0.8)$ & $<0.0001$ & $<0.0001$ & $<0.0001$ \\
\hline \multicolumn{7}{|l|}{ Urbanisation, n(\%) } \\
\hline Rural & $256(48.1)$ & $30,186(48.8)$ & $335,594(46.9)$ & & & \\
\hline Urban & $276(51.9)$ & $31,649(51.2)$ & $380,162(53.1)$ & 0.7489 & 0.5687 & $<0.0001$ \\
\hline \multicolumn{7}{|l|}{ Income, $\mathrm{n}(\%)$} \\
\hline$\leq 17,280$ & $307(57.7)$ & $22,329(36.1)$ & $425,699(59.5)$ & & & \\
\hline $17,281-22,880$ & $181(34.0)$ & $25,695(41.6)$ & $172,793(24.1)$ & & & \\
\hline $22,881-28,800$ & $19(3.6)$ & $3110(5.0)$ & $29,330(4.1)$ & & & \\
\hline $28,801-36,300$ & $8(1.5)$ & $3727(6.0)$ & $32,903(4.6)$ & & & \\
\hline $36,301-45,800$ & $13(2.4)$ & $3374(5.5)$ & $26,840(3.7)$ & & & \\
\hline$>45,800$ & $4(0.8)$ & $3600(5.8)$ & $28,191(3.9)$ & $<0.0001$ & $<0.0001$ & $<0.0001$ \\
\hline \multicolumn{7}{|l|}{ Comorbidities, n (\%) ${ }^{\mathrm{a}}$} \\
\hline Myocardial infarction & $0(0.0)$ & $786(1.3)$ & $1537(0.2)$ & 0.0089 & 0.2846 & $<0.0001$ \\
\hline Congestive heart failure & $30(5.6)$ & $4261(6.9)$ & $9964(1.4)$ & 0.2560 & $<0.0001$ & $<0.0001$ \\
\hline Peripheral vascular disease & $12(2.3)$ & $3081(5.0)$ & $8395(1.2)$ & 0.0039 & 0.0205 & $<0.0001$ \\
\hline Hemiplegia or paraplegia & $10(1.9)$ & $1245(2.0)$ & $4784(0.7)$ & 0.8269 & 0.0006 & $<0.0001$ \\
\hline Renal disease & $20(3.8)$ & $3417(5.5)$ & $7375(1.0)$ & 0.0754 & $<0.0001$ & $<0.0001$ \\
\hline Cerebrovascular disease & $51(9.6)$ & $8225(13.3)$ & $20,217(2.8)$ & 0.0119 & $<0.0001$ & $<0.0001$ \\
\hline $\mathrm{CCI}$, mean $(\mathrm{SD})^{\mathrm{b}}$ & $1.1(1.6)$ & $1.3(1.7)$ & $0.5(1.0)$ & 0.0644 & $<0.0001$ & $<0.0001$ \\
\hline \multicolumn{7}{|l|}{$\mathrm{CCI}, \mathrm{n}(\%)$} \\
\hline 0 & $271(50.9)$ & $30,182(48.8)$ & $537,997(75.2)$ & & & \\
\hline $1-2$ & $168(31.6)$ & $19,239(31.1)$ & 142,206 (19.9) & & & \\
\hline$>2$ & $93(17.5)$ & $12,414(20.1)$ & $35,553(5.0)$ & 0.3170 & $<0.0001$ & $<0.0001$ \\
\hline \multicolumn{7}{|l|}{ Diabetes duration, n (\%) } \\
\hline$\leq 3$ years & $188(35.3)$ & $16,934(27.4)$ & & & & \\
\hline $3-6$ years & $91(17.1)$ & $10,751(17.4)$ & & & & \\
\hline $6-9$ years & $98(18.4)$ & $11,615(18.8)$ & & & & \\
\hline$>9$ years & $155(29.1)$ & $22,535(36.4)$ & & 0.0002 & $<0.0001$ & $<0.0001$ \\
\hline
\end{tabular}

Note: T2DM: type 2 diabetes mellitus; GP: General population; SD: standard deviation; Income: Taiwan New Dollar (NTD).

a Comorbidities was defined as $\geq 3$ outpatient claims.

b $\mathrm{CCI}$ : Charlson comorbidity index for each comorbidity was defined as $\geq 3$ outpatient claims.

c $T$-tests were used to compare continuous variables and chi-square tests were used to compare categorical variables between two groups. The significant levels were

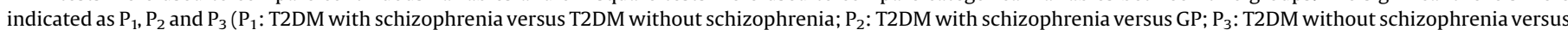
GP). 


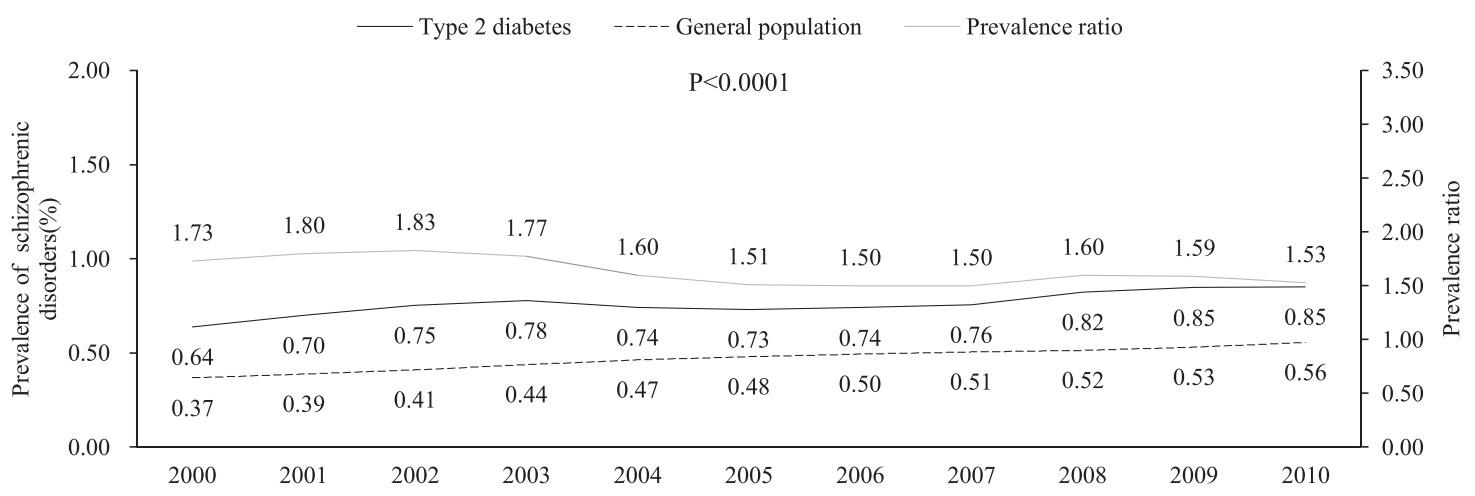

Fig. 1. Prevalence of schizophrenia in persons with type 2 diabetes mellitus and general population, prevalence ratios of schizophrenia.

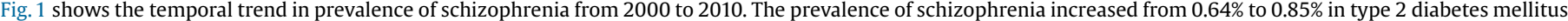

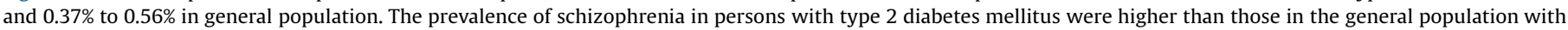
significant difference from 2000 to 2010 ( $\mathrm{p}<0.0001$ ).

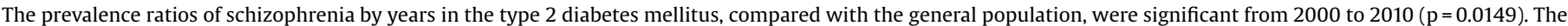
type 2 diabetes mellitus-to-general population decreased from 1.73 in 2000 to 1.53 in 2010 .

T2DM group were significant from 2000 to 2010 compared with the GP group ( $\mathrm{P}=0.0149)$. The ratio decreased from 1.73 in 2000 to 1.53 in 2010.

Table 2 compares the prevalence of schizophrenia between the T2DM and GP groups in 2010. The 1-year prevalence rate of schizophrenia was significantly higher in the T2DM group than in the GP group $(0.85 \%$ vs. $0.56 \%$; PR: 1.53 ; 95\% CI: $1.39-1.67$; $\mathrm{P}<0.0001)$. The 1 -year prevalence of schizophrenia was higher in patients with T2DM who had received ADT than in the GP $(0.84 \%$ vs. $0.56 \%$ ) and higher in patients with T2DM who had not received ADT than in the GP $(0.91 \%$ vs. $0.56 \%)$. Patients with the following characteristics had a higher prevalence of schizophrenia in the T2DM group than in the GP group: those aged 20-30, 31-40, 4150 , or 51-60 years; men and women; those residing in all areas except for central Taiwan and offshore islets; those living in urban and rural areas; those with incomes of $\leq \mathrm{NT} \$ 17,280$, NT\$17,281-NT $\$ 22,880$, NT\$22,881-NT\$28,800, NT\$36,301-NT\$45,800; and those with CCI scores of 0 and 1-2.

Table 3 shows the results of multiple logistic regression analysis for factors associated with the prevalence of schizophrenia in patients with T2DM. The prevalence of schizophrenia in patients with T2DM was associated with the ages of 31-40 and 41-50 years; residence in eastern Taiwan; income of $\leq \mathrm{NT} \$ 17,280$, NT\$17,281NT\$22,880, NT\$22,881-NT\$28,800, or NT\$36,301-NT\$45,800; and $\mathrm{CCI}>2$; however, the prevalence was lower in patients aged $\geq 80$ years and those prescribed thiazolidinediones.

\section{Discussion}

This study was the first to use the population-based NHI dataset to estimate the prevalence of schizophrenia in patients with T2DM and the GP in Taiwan. Because the NHI program covers $98 \%$ of Taiwan's population, the prevalence data obtained from this study approximated the actual distribution of schizophrenia in patients with T2DM and in the GP in Taiwan. To the best of our knowledge, few or no real-world data are available regarding diagnoses of schizophrenia in patients with T2DM. Most previous studies have focused on the prevalence of T2DM in patients with schizophrenia rather than that of schizophrenia in patients with T2DM [31-33]. Another unique feature of the current study was that it analysed a specific Asian population (i.e., ethnic Han Chinese).

Our study findings indicated that 1-year prevalence of schizophrenia in 2010 was higher in the T2DM group (0.85\%) than in the GP group (0.56\%). From 2000 to 2010, the prevalence of schizophrenia was significantly higher in the T2DM group $(0.64 \%-$ $0.85 \%)$ than in the GP group $(0.37 \%-0.56 \%)$ and the relative risk significantly increased from a factor of 1.53 to one of 1.73 (Fig. 1). In 2010 , the 1-year prevalence of treated schizophrenia in the GP was $0.56 \%$, which was lower than the corresponding prevalence of $1.25 \%$ in Hong Kong [34]. However, Chien et al. showed that the cumulative prevalence of schizophrenia in the GP increased from $0.33 \%$ to $0.64 \%$ from 1996 to 2001 in Taiwan [29].

In addition, we found compared with GP, the prevalence of schizophrenia was observed significantly higher in patients with T2DM with earlier ages less than 60 years old (Table2). Supposedly, prevalence is the proportion of a population that has a condition at a specific time, and will be influenced by both the rate at which incident cases are occurring and the average duration of the disease [35]. Therefore, the prevalence of schizophrenia in patients with T2DM may not only reflect the proportion of a T2DM population that has onset risk of schizophrenia at a certain point of time before they developed T2DM, but also the potential premature mortality risks that may affect the duration of the schizophrenia in patients with T2DM $[6,36]$. If an effective intervention program can reduce premature mortality, the prevalence will increase, holding the incidence rate of schizophrenia constant. Effective intervention can be suicide prevention program, or non-suicidal prevention program such as life style change intervention or improvement compliance in diabetes and schizophrenia treatments for reducing potential premature death due to diabetes or cardiovascular diseases [36-38].

Table 3 shows the results of multiple logistic regression analyses for factors associated with the prevalence of schizophrenia in patients with T2DM. No such information on the factors of schizophrenia in patients with T2DM was previously available. The prevalence of schizophrenia in patients with T2DM was highest in those aged $31-40$ and $41-50$ years and lowest in those aged $\geq 80$ years. A study conducted in Taiwan revealed that advanced age was an independent factor associated with DM in patients with schizophrenia [23]. In our study, an increased prevalence of schizophrenia in patients with T2DM was observed in those residing in eastern Taiwan; this could have been attributed to the presence of two large psychiatric hospitals in this region. In addition, most of our patients were at a relatively low income level; low socioeconomic status is a risk factor of DM [39]. CCI $>2$ is another risk factor that was revealed in our study. Hypertension and hyperlipidaemia were the risk factors of diabetes in patients with schizophrenia in a previous study from Taiwan [22]. A significant difference in the usage of thiazolidinediones exists among patients with T2DM and schizophrenia. Schizophrenia and antipsychotic agents induce metabolic syndrome and obesity. In addition, thiazolidinediones induce weight gain though various 
Table 2

Prevalence of schizophrenia in patients with type 2 DM and general population in year 2010.

\begin{tabular}{|c|c|c|c|c|c|c|c|c|}
\hline & \multicolumn{3}{|c|}{ Type 2 diabetes mellitus } & \multicolumn{3}{|c|}{ General population } & \multirow{2}{*}{$\begin{array}{l}\text { Type } 2 \text { diabetes } \\
\text { mellitus } \\
\text { vs general } \\
\text { population } \\
\text { Prevalence } \\
\text { ratio(95\% CI) }\end{array}$} & \multirow[b]{2}{*}{$\mathrm{P}$ value } \\
\hline & $\begin{array}{l}\text { Schizophrenia, } \\
\text { n }\end{array}$ & $\begin{array}{l}\text { At risk } \\
\text { population, } \mathrm{n}\end{array}$ & $\begin{array}{l}\text { Prevalence (\%) } \\
(95 \% \mathrm{CI})\end{array}$ & $\begin{array}{l}\text { Schizophrenia, } \\
\text { n }\end{array}$ & $\begin{array}{l}\text { At risk } \\
\text { population, } \mathrm{n}\end{array}$ & $\begin{array}{l}\text { Prevalence }(\%) \\
(95 \% \mathrm{CI})\end{array}$ & & \\
\hline Total (overall) & 532 & 62367 & $0.85(0.78-0.93)$ & 4002 & 715,756 & $0.56(0.54-0.58)$ & $1.53(1.39-1.67)$ & $<0.0001$ \\
\hline \multicolumn{9}{|l|}{ Age group (years) } \\
\hline $20-30$ & 5 & 502 & $0.81(0.34-1.95)$ & 615 & 150,017 & $0.33(0.31-0.37)$ & $2.43(1.01-5.84)$ & 0.0473 \\
\hline $31-40$ & 58 & 1013 & $2.40(1.86-3.11)$ & 2416 & 168,180 & $0.60(0.57-0.64)$ & $3.99(3.07-5.18)$ & $<0.0001$ \\
\hline $41-50$ & 145 & 1194 & $1.95(1.66-2.29)$ & 7442 & 154,120 & $0.77(0.73-0.82)$ & $2.51(2.12-2.98)$ & $<0.0001$ \\
\hline $51-60$ & 187 & 829 & $1.12(0.97-1.29)$ & 16,674 & 125,318 & $0.66(0.62-0.71)$ & $1.70(1.45-1.99)$ & $<0.0001$ \\
\hline $61-70$ & 73 & 294 & $0.45(0.36-0.56)$ & 16,274 & 59,114 & $0.50(0.44-0.56)$ & $0.90(0.70-1.16)$ & 0.4288 \\
\hline $71-80$ & 52 & 123 & $0.41(0.31-0.53)$ & 12,833 & 37,519 & $0.33(0.27-0.39)$ & $1.24(0.89-1.71)$ & 0.1993 \\
\hline$>80$ & 12 & 47 & $0.20(0.11-0.35)$ & 6113 & 21,488 & $0.22(0.16-0.29)$ & $0.90(0.48-1.69)$ & 0.7378 \\
\hline \multicolumn{9}{|c|}{ (1) - } \\
\hline Males & 243 & 2078 & $0.78(0.69-0.88)$ & 31,267 & 345,736 & $0.60(0.58-0.63)$ & $1.29(1.13-1.48)$ & 0.0001 \\
\hline Females & 289 & 1924 & $0.93(0.83-1.04)$ & 31,100 & 370,020 & $0.52(0.5-0.54)$ & $1.79(1.58-2.02)$ & $<0.0001$ \\
\hline \multicolumn{9}{|l|}{ Region } \\
\hline Northern & 237 & 1830 & $0.83(0.73-0.95)$ & 28,477 & 343,067 & $0.53(0.51-0.56)$ & 1.56 (1.36-1.79) & $<0.0001$ \\
\hline Central & 99 & 946 & $0.69(0.57-0.84)$ & 14,374 & 167,093 & $0.57(0.53-0.60)$ & $1.22(0.99-1.50)$ & 0.0626 \\
\hline Southern & 161 & 1061 & $0.94(0.80-1.09)$ & 17,198 & 183,341 & $0.58(0.54-0.61)$ & $1.62(1.37-1.91)$ & $<0.0001$ \\
\hline Eastern & 31 & 132 & $1.83(1.29-2.60)$ & 1696 & 16,174 & $0.82(0.69-0.97)$ & $2.24(1.52-3.30)$ & $<0.0001$ \\
\hline $\begin{array}{l}\text { Offshore islets and } \\
\text { other }\end{array}$ & 4 & 33 & $0.64(0.24-1.71)$ & 622 & 6081 & $0.54(0.39-0.76)$ & $1.19(0.42-3.33)$ & 0.7477 \\
\hline \multicolumn{9}{|l|}{ Urbanisation } \\
\hline Rural & 256 & 1995 & $0.84(0.74-0.95)$ & 30,442 & 335,594 & $0.59(0.57-0.62)$ & $1.41(1.24-1.61)$ & $<0.0001$ \\
\hline Urban & 276 & 2007 & $0.86(0.77-0.97)$ & 31,925 & 380,162 & $0.53(0.51-0.55)$ & $1.64(1.44-1.86)$ & $<0.0001$ \\
\hline \multicolumn{9}{|l|}{ Income } \\
\hline$\leq 17,280$ & 307 & 2782 & $1.36(1.21-1.52)$ & 22,636 & 425,699 & $0.65(0.63-0.68)$ & $2.08(1.85-2.33)$ & $<0.0001$ \\
\hline $17,281-22,880$ & 181 & 971 & $0.70(0.60-0.81)$ & 25,876 & 172,793 & $0.56(0.53-0.60)$ & $1.24(1.06-1.46)$ & 0.0067 \\
\hline $22,881-28,800$ & 19 & 93 & $0.61(0.39-0.95)$ & 3129 & 29,330 & $0.32(0.26-0.39)$ & $1.92(1.17-3.13)$ & 0.0097 \\
\hline $28,801-36,300$ & 8 & 88 & $0.21(0.11-0.43)$ & 3735 & 32,903 & $0.27(0.22-0.33)$ & $0.80(0.39-1.65)$ & 0.5471 \\
\hline $36301-45,800$ & 13 & 41 & $0.38(0.22-0.66)$ & 3387 & 26,840 & $0.15(0.11-0.21)$ & $2.51(1.35-4.68)$ & 0.0037 \\
\hline$>45,800$ & 4 & 27 & $0.11(0.04-0.30)$ & 3604 & 28,191 & $0.10(0.07-0.14)$ & $1.16(0.41-3.31)$ & 0.7831 \\
\hline \multicolumn{9}{|l|}{ Comorbidities } \\
\hline $\begin{array}{l}\text { Myocardial } \\
\text { infarction }\end{array}$ & 0 & 2 & - & 786 & 1537 & $0.13(0.03-0.52)$ & - & - \\
\hline $\begin{array}{l}\text { Congestive heart } \\
\text { failure }\end{array}$ & 30 & 58 & $0.70(0.49-1.00)$ & 4291 & 9964 & $0.58(0.45-0.75)$ & $1.20(0.77-1.86)$ & 0.4137 \\
\hline $\begin{array}{l}\text { Peripheral vascular } \\
\text { disease }\end{array}$ & 12 & 45 & $0.39(0.22-0.68)$ & 3093 & 8395 & $0.54(0.40-0.72)$ & $0.72(0.38-1.37)$ & 0.3187 \\
\hline $\begin{array}{l}\text { Hemiplegia or } \\
\text { paraplegia }\end{array}$ & 10 & 36 & $0.80(0.43-1.48)$ & 1255 & 4784 & $0.75(0.54-1.04)$ & $1.06(0.53-2.13)$ & 0.8724 \\
\hline Renal disease & 20 & 46 & $0.58(0.38-0.90)$ & 3437 & 7375 & $0.62(0.47-0.83)$ & $0.93(0.55-1.57)$ & 0.7949 \\
\hline $\begin{array}{l}\text { Cerebrovascular } \\
\text { disease }\end{array}$ & 51 & 159 & $0.62(0.47-0.81)$ & 8276 & 20,217 & $0.79(0.67-0.92)$ & $0.78(0.57-1.07)$ & 0.1283 \\
\hline \multicolumn{9}{|l|}{$\mathrm{CCI}$} \\
\hline 0 & 271 & 2779 & $0.89(0.79-1.00)$ & 30,453 & 537,997 & $0.52(0.50-0.54)$ & $1.72(1.52-1.95)$ & $<0.0001$ \\
\hline $1-2$ & 168 & 972 & $0.87(0.74-1.01)$ & 19,407 & 142,206 & $0.68(0.64-0.73)$ & $1.27(1.08-1.49)$ & 0.0045 \\
\hline$>2$ & 93 & 251 & $0.74(0.61-0.91)$ & 12,507 & 35,553 & $0.71(0.62-0.8)$ & $1.05(0.83-1.34)$ & 0.6680 \\
\hline \multicolumn{9}{|l|}{ Anti-diabetic therapy } \\
\hline $\mathrm{No}^{\mathrm{a}}$ & 106 & 11622 & $0.91(0.75-1.10)$ & 4002 & 715,756 & $0.56(0.54-0.58)$ & $1.63(1.35-1.98)$ & $<0.0001$ \\
\hline Yes $^{\mathrm{b}}$ & 426 & 50745 & $0.84(0.76-0.92)$ & 4002 & 715,756 & $0.56(0.54-0.58)$ & $1.50(1.36-1.66)$ & $<0.0001$ \\
\hline
\end{tabular}

Note: MDD: major depressive disorder; T2DM: type 2 diabetes mellitus; Income: New Taiwan Dollar (NTD); “-“, no calculated.

Comorbidities was defined as $>3$ outpatient claims.

CCI: Charlson comorbidity index for each comorbidity was defined as $\geq 3$ outpatient claims.

Prevalence ratio with $95 \%$ confidence interval (CI) was estimated by a generalized linear mixed models, assuming a Poisson distribution.

Anti-diabetic therapy was defined as $>3$ outpatient claims.

Prevalence ratio with $95 \%$ confidence interval (CI) was estimated by the log-binomial model.

a Type 2 diabetes patients without anti-diabetic therapy compared with the general population.

b Type 2 diabetes patients with anti-diabetic therapy compared with the general population.

mechanisms. Hence, their use is not recommended for patients with T2DM and schizophrenia to prevent further weight gain, which can lead to adverse cardiovascular outcomes [40]. By contrast, thiazolidinediones exert a neuroprotective effect through stabilizing a patient's metabolic profile and anti-inflammation to eliminate psychological symptoms [41].

The present study estimated the prevalence of schizophrenia in a large, randomly selected, population-based NHI sample of patients with T2DM, and also in the GP. Insurance data are useful for studying the prevalence of schizophrenia in patients with
T2DM because of the numerous patients available for data sampling. Using a health insurance database eliminates the need to spend money and conduct time-consuming psychiatric assessments, as well as the need to collect longitudinal data on the prevalence of schizophrenia and its associated risk factors [26,29]. However, several limitations needed to be addressed. First, the limitations of a database study may still exist regarding the potential for inconsistencies in the diagnostic criteria for schizophrenia or T2DM, reduced reliability and validity of secondary data, dual diagnoses, and over- and under-diagnosis 
Table 3

Adjusted odds ratio of factors with prevalence of schizophrenia in persons with type 2 diabetes mellitus in year $2010(\mathrm{~N}=62,367)$.

\begin{tabular}{|c|c|c|}
\hline & Adjusted OR (95\% CI) & $P$ value \\
\hline \multicolumn{3}{|l|}{ Age group (years) } \\
\hline $20-30$ & 1.00 & \\
\hline $31-40$ & $3.56(1.42-8.93)$ & 0.0069 \\
\hline $41-50$ & $3.98(1.61-9.83)$ & 0.0027 \\
\hline $51-60$ & $2.37(0.96-5.84)$ & 0.0614 \\
\hline $61-70$ & $0.90(0.36-2.27)$ & 0.8217 \\
\hline $71-80$ & $0.67(0.26-1.72)$ & 0.4044 \\
\hline$>80$ & $0.25(0.09-0.72)$ & 0.0100 \\
\hline \multicolumn{3}{|l|}{ Sex } \\
\hline Males & 1.00 & \\
\hline Females & $1.15(0.97-1.38)$ & 0.1137 \\
\hline \multicolumn{3}{|l|}{ Region } \\
\hline Northern & 1.00 & \\
\hline Central & $0.78(0.60-1.02)$ & 0.0661 \\
\hline Southern & $1.08(0.87-1.34)$ & 0.4761 \\
\hline Eastern & $2.29(1.51-3.45)$ & $<0.0001$ \\
\hline Offshore islets and other & $0.91(0.33-2.49)$ & 0.8539 \\
\hline \multicolumn{3}{|l|}{ Urbanization } \\
\hline Rural & 1.00 & \\
\hline Urban & $0.98(0.80-1.20)$ & 0.8684 \\
\hline \multicolumn{3}{|l|}{ Income } \\
\hline$\leq 17,280$ & $13.74(5.09-37.07)$ & $<0.0001$ \\
\hline $17281-22880$ & $7.07(2.61-19.14)$ & 0.0001 \\
\hline $22,881-28,800$ & $5.33(1.81-15.72)$ & 0.0024 \\
\hline $28,801-36,300$ & $1.90(0.57-6.31)$ & 0.2963 \\
\hline $36,301-45,800$ & 3.67 (1.19-11.27) & 0.0233 \\
\hline$>45,800$ & 1.00 & \\
\hline \multicolumn{3}{|l|}{ Comorbidities } \\
\hline Myocardial infarction & - & - \\
\hline Congestive heart failure & $1.12(0.75-1.68)$ & 0.5659 \\
\hline Peripheral vascular disease & $0.56(0.31-1.00)$ & 0.0515 \\
\hline Hemiplegia or paraplegia & $0.94(0.48-1.81)$ & 0.8447 \\
\hline Renal disease & $0.72(0.44-1.18)$ & 0.1909 \\
\hline Cerebrovascular disease & $1.04(0.75-1.44)$ & 0.8213 \\
\hline \multicolumn{3}{|l|}{$\mathrm{CCI}$} \\
\hline 0 & 1.00 & \\
\hline $1-2$ & $1.06(0.87-1.30)$ & 0.5481 \\
\hline$>2$ & $1.43(1.05-1.94)$ & 0.0220 \\
\hline \multicolumn{3}{|l|}{ Diabetes duration } \\
\hline$\leq 3$ years & 1.00 & \\
\hline $3-6$ years & $0.90(0.69-1.18)$ & 0.4621 \\
\hline $6-9$ years & $1.06(0.80-1.39)$ & 0.6926 \\
\hline$>9$ years & $1.21(0.92-1.59)$ & 0.1783 \\
\hline \multicolumn{3}{|l|}{ Oral anti-diabetic therapy ${ }^{a}$} \\
\hline Metformin (A10BA) & $1.25(0.99-1.58)$ & 0.0654 \\
\hline Sulfonylureas (A10BB) & $0.85(0.67-1.07)$ & 0.1653 \\
\hline Meglitinides (A10BX) & $1.19(0.91-1.57)$ & 0.2110 \\
\hline Thiazolidinediones (A10BG) & $0.62(0.48-0.81)$ & 0.0005 \\
\hline$\alpha$-glucosidase inhibitor (A10BF) & $1.05(0.82-1.34)$ & 0.7138 \\
\hline \multicolumn{3}{|l|}{ Insulin injection therapy } \\
\hline Rapid-acting (A10AB), & $1.20(0.82-1.76)$ & 0.3432 \\
\hline Intermediate-acting (A10AC) & $0.91(0.55-1.51)$ & 0.7124 \\
\hline Long-acting (A10AE) & $1.24(0.76-2.04)$ & 0.3874 \\
\hline Combination (A10AD), & $0.53(0.28-1.01)$ & 0.0549 \\
\hline
\end{tabular}

Income: New Taiwan Dollar (NTD).

Comorbidities was defined as $\geq 3$ outpatient claims.

CCI: Charlson comorbidity index for each comorbidity was defined as $\geq 3$ outpatient claims.

a Oral anti-diabetic therapy and insulin injection therapy for each Anatomical Therapeutic Chemical (ATC) code were defined as $\geq 3$ outpatient claims.

$[26,42,43]$. Nevertheless, one study by Chien et al. compared prevalence of psychiatric disorders among National Health Insurance enrolees in Taiwan and the results from community survey study. Their prevalence results were validated and within the range of other previous community survey study. The prevalence of schizophrenic disorder (ICD-9-CM 295) was about $0.44 \%$ in year 2000 [30]. Second, several essential variables were not assessed in the administrative claim data, including lifestyle factors, physical activity, educational level, occupation, marital status, blood glucose control, glycaemic level, and body weight. Third, given the study data periods from year 2000 , we could not track the number of years since type 2 diabetes or schizophrenia were diagnosed or identify whether patients were newly diagnosed. Future study may further look at the prevalence of schizophrenia in patients who developed type 2 diabetes to examine if antipsychotic treatment may have inflated the rate of T2DM in those with schizophrenia. Finally, differences in genetics, obesity levels, diets, cultures, lifestyles, and medical resources may exist between ethnic Han Chinese and Western populations [26]. The study results from populations in Taiwan may not be generalized to other populations in other counties.

In conclusion, this study found the prevalence of schizophrenia from 2000 to 2010 was significantly higher in patients with T2DM than in the GP, and the prevalence of schizophrenia increased from $0.64 \%$ to $0.85 \%$ in patients with T2DM from 2000 to 2010 . Compared with GP, the prevalence of schizophrenia was observed higher in patients with T2DM with less than 60 years old. These results suggest that physicians and public health officials must develop effective prevention and treatment strategies to carefully care those patients who were comorbid with both T2DM and schizophrenia, particularly those who have the potential premature mortality risks that may affect the duration of the schizophrenia in patients with T2DM.

\section{Conflict of interests}

We declare that none of the authors has a conflict of interest with regard to this manuscript.

\section{Acknowledgements}

This study was supported by a grant from Kaohsiung Medical University Hospital (KMUH105-5T08). This study is based in part on data from the National Health Insurance Research Database provided by the Bureau of National Health Insurance, Department of Health and managed by National Health Research Institutes (NHIRD-100-100 and NHIRD-102-135). The interpretation and conclusions contained herein do not represent those of the aforementioned agencies. This manuscript was edited by Wallace Academic Editing.

\section{References}

[1] Suvisaari J., Keinanen J, Eskelinen S, Mantere O. Diabetes and schizophrenia. Curr Diabetes Rep 2016;16:16.

[2] Pedersen CB, Mors O, Bertelsen A, Waltoft BL, Agerbo E, McGrath JJ, et al. A comprehensive nationwide study of the incidence rate and lifetime risk for treated mental disorders. JAMA Psychiatry 2014;71:573-81.

[3] Perälä J, Suvisaari J, Saarni SI, Kuoppasalmi K, Isometsä E, Pirkola S, et al. Lifetime prevalence of psychotic and bipolar I disorders in a general population. Arch Gen Psychiatry 2007:64:19-28.

[4] Laursen TM, Munk-Olsen T, Vestergaard M. Life expectancy and cardiovascular mortality in persons with schizophrenia. Curr Opin Psychiatry 2012;25:83-8.

[5] Leng $\mathrm{CH}$, Chou MH, Lin SH, Yang YK, Wang JD. Estimation of life expectancy, loss-of-life expectancy, and lifetime healthcare expenditures for schizophrenia in Taiwan. Schizophr Res 2016;171:97-102.

[6] Hjorthoj C, Sturup AE, McGrath JJ, Nordentoft M. Years of potential life lost and life expectancy in schizophrenia: a systematic review and meta-analysis. Lancet Psychiatry 2017;4:295-301.

[7] ADA. Classification and Diagnosis of Diabetes: Standards of Medical Care in Diabetes-2018 [American Dibetes Association]. Diabetes Care 2018;41:S13-27.

[8] Lin WH, Hsu CH, Chen HF, Liu CC, Li CY. Mortality of patients with type 2 diabetes in Taiwan: a 10-year nationwide follow-up study. Diabetes Res Clin Pract 2015;107:178-86.

[9] Amos AF, McCarty DJ, Zimmet P. The rising global burden of diabetes and its complications: estimates and projections to the year 2010. Diabetes Med 1997; 14(Suppl. 5):S1-85.

[10] Quan J, Li TK, Pang H, Choi CH, Siu SC, Tang SY, et al. Diabetes incidence and prevalence in Hong Kong, China during 2006-2014. Diabetes Med 2017;34:902-8.

[11] Rajkumar AP, Horsdal HT, Wimberley T, Cohen D, Mors O, Børglum AD, et al. Endogenous and antipsychotic-related risks for diabetes mellitus in young people with schizophrenia: a Danish population-based cohort study. Am J Psychiatry 2017;174:686-94. 
[12] Maudsley H. The pathology of mind. London: Macmillan; 1879.

[13] Andreassen OA. Diabetes and schizophrenia-new findings for an old puzzle. Am J Psychiatry 2017;174:616-7.

[14] Raphael T, Parsons JP. Blood sugar studies in dementia praecox and manicdepressive insanity. Arch Neurol Psychiatry 1921;5:687-709.

[15] Ryan MC, Thakore JH. Physical consequences of schizophrenia and its treatment: the metabolic syndrome. Life Sci 2002;71:239-57.

[16] Polimanti R, Gelernter J, Stein DJ. Genetically determined schizophrenia is not associated with impaired glucose homeostasis. Schizophr Res 2018;195:2869.

[17] Foley DL, Mackinnon A, Morgan VA, Watts GF, Castle DJ, Waterreus A, et al. Common familial risk factors for schizophrenia and diabetes mellitus. Aust N Z J Psychiatry 2016;50:488-94.

[18] Hansen T, Ingason A, Djurovic S, Melle I, Fenger M, Gustafsson O, et al. At-risk variant in TCF7L2 for type II diabetes increases risk of schizophrenia. Biol Psychiatry 2011;70:59-63.

[19] Liu Y, Li Z, Zhang M, Deng Y, Yi Z, Shi T. Exploring the pathogenetic association between schizophrenia and type 2 diabetes mellitus diseases based on pathway analysis. BMC Med Genomics 2013;6:S17.

[20] Andreassen OA, Djurovic S, Thompson WK, Schork AJ, Kendler KS, O’Donovan $\mathrm{MC}$, et al. Improved detection of common variants associated with schizophrenia by leveraging pleiotropy with cardiovascular-disease risk factors. Am J Hum Genet 2013;92:197-209.

[21] Chien IC, Hsu JH, Lin CH, Bih SH, Chou YJ, Chou P. Prevalence of diabetes in patients with schizophrenia in Taiwan: a population-based National Health Insurance study. Schizophr Res 2009;111:17-22.

[22] Hsu JH, Chien IC, Lin CH, Chou YJ, Chou P. Incidence of diabetes in patients with schizophrenia: a population-based study. Can J Psychiatry 2011;56:19-26.

[23] Hung CF, Wu CK, Lin PY. Diabetes mellitus in patients with schizophrenia in Taiwan. Prog Neuropsychopharmacol Biol Psychiatry 2005;29:523-7.

[24] Stubbs B, Vancampfort D, De Hert M, Mitchell AJ. The prevalence and predictors of type two diabetes mellitus in people with schizophrenia: a systematic review and comparative meta-analysis. Acta Psychiatr Scand 2015;132:144-57.

[25] Vancampfort D, Correll CU, Galling B, Probst M, De Hert M, Ward PB, et al. Diabetes mellitus in people with schizophrenia, bipolar disorder and major depressive disorder: a systematic review and large scale meta-analysis. World Psychiatry 2016;15:166-74.

[26] Huang CJ, Lin CH, Lee MH, Chang KP, Chiu HC. Prevalence and incidence of diagnosed depression disorders in patients with diabetes: a national population-based cohort study. Gen Hosp Psychiatry 2012;34:242-8.

[27] Huang CJ, Chiu HC, Lee MH, Wang SY. Prevalence and incidence of anxiety disorders in diabetic patients: a national population-based cohort study. Gen Hosp Psychiatry 2011;33:8-15.

[28] Huang CJ, Chiu HC, Hsieh HM, Yen JY, Lee MH, Chang KP, et al. Health care utilization and expenditures of persons with diabetes comorbid with anxiety disorder: a national population-based cohort study. Gen Hosp Psychiatry 2015;37:299-304

[29] Chien IC, Chou YJ, Lin CH, Bih SH, Chou P, Chang HJ. Prevalence and incidence of schizophrenia among National Health Insurance enrollees in Taiwan, 19962001. Psychiatry Clin Neurosci 2004;58:611-8.

[30] Chien IC, Chou YJ, Lin CH, Bih SH, Chou P. Prevalence of psychiatric disorders among National Health Insurance enrollees in Taiwan. Psychiatr Serv 2004;55:691-7.

[31] Stubbs B, Vancampfort D, De Hert M, Mitchell A. The prevalence and predictors of type two diabetes mellitus in people with schizophrenia: a systematic review and comparative meta-analysis. Acta Psychiatr Scand 2015;132:14457.

[32] Shafie S, Lee SP, Ong SBC, Wang P, Seow E, Ong HL, et al. Prevalence and correlates of diabetes mellitus and dyslipidaemia in a long-stay inpatient schizophrenia population in Singapore. Singapore Med J 2018, doi:http://dx. doi.org/10.11622/smedj.2018020 [Epub ahead of print].

[33] Sugai T, Suzuki Y, Yamazaki M, Shimoda K, Mori T, Ozeki Y, et al. High prevalence of obesity, hypertension, hyperlipidemia, and diabetes mellitus in Japanese outpatients with schizophrenia: a nationwide survey. PLoS One 2016;11:e0166429.

[34] Chang WC, Wong CSM, Chen EYH, Lam LCW, Chan WC, Ng RMK, et al. Lifetime prevalence and correlates of schizophrenia-spectrum, affective, and other non-affective psychotic disorders in the Chinese adult population. Schizophr Bull 2017;43:1280-90.

[35] Aschengrau A, Seage [223_TD\$DIFF]III GR. Essentials of epidemiology in public health. third edition MA, USA: Jones \& Bartlett Learning; 2014.

[36] Galletly CA. Premature death in schizophrenia: bridging the gap. Lancet Psychiatry 2017;4:263-5.

[37] Olfson M, Gerhard T, Huang C, Crystal S, Stroup TS. Premature mortality among adults with schizophrenia in the United States. JAMA Psychiatry 2015;72:1172-81.

[38] Suetani S, Whiteford HA, McGrath JJ. An urgent call to address the deadly consequences of serious mental disorders. JAMA Psychiatry 2015;72:1166-7.

[39] Hoffman RP. The complex inter-relationship between diabetes and schizophrenia. Curr Diabetes Rev 2017;13:528-32.

[40] Wilding J. The importance of weight management in type 2 diabetes mellitus. Int J Clin Pract 2014;68:682-91.

[41] Smith RC, Jin H, Li C, Bark N, Shekhar A, Dwivedi S, et al. Effects of pioglitazone on metabolic abnormalities, psychopathology, and cognitive function in schizophrenic patients treated with antipsychotic medication: a randomized double-blind study. Schizophr Res 2013;143:18-24.

[42] Liptzin B, Regier DA, Goldberg ID. Utilization of health and mental health services in a large insured population. Am J Psychiatry 1980;137:553-8.

[43] Katon WJ, Rutter C, Simon G, Lin EH, Ludman E, Ciechanowski P, et al. The association of comorbid depression with mortality in patients with type 2 diabetes. Diabetes Care 2005;28:2668-72. 